\title{
The prevalence of amblyopia in 7-9-year-old schoolchildren in Mashhad
}

\author{
Saeed Shahpary ${ }^{1}$, Shahrokh Ramin ${ }^{1}$, Abbas Azimi ${ }^{2}$ and Mohsen Heyrani ${ }^{2}$ \\ ${ }^{1}$ Department of Optometry, School of Rehabilitation Sciences, Shahid Beheshti University of Medical Sciences, \\ Tehran, Iran \\ ${ }^{2}$ Refractive Errors Research Center, School of Paramedical Sciences, Mashhad University of Medical Sciences, \\ Mashhad, Iran
}

\begin{abstract}
Background: To determine the prevalence of amblyopia in schoolchildren aged 7-9 years old in Mashhad, Iran.

Methods: This was a cross-sectional, community-based study with schoolchildren aged 7-9 years old. We randomly selected 20 of 189 elementary schools (three schools per district; 10 male-segregated and 10 female-segregated schools) from a proportional combination of public schools across Mashhad. Basic vision exams were performed. If amblyopia was suspected, children underwent supplementary vision exams. The diagnostic criterion for amblyopia was a best corrected visual acuity (BCVA) in one or both eyes equal to or worse than 20/40 or an interocular difference of more than two lines in BCVA without any significant organic pathology.

Results: A total of 2831 children were included in the study. All children were examined comprehensively by an optometrist, and amblyopia was detected in 49/2831 (1.7\% [95\% CI, 1.22-2.18]). Of the 49 children with amblyopia, $20(40.8 \%)$ were amblyopic in the right eye, $9(18.4 \%)$ in the left eye, and $20(40.8 \%)$ in both eyes. Twenty-four (49\%) were first graders, 15 (30.6\%) were second graders, and $10(20.4 \%)$ were third graders. The most prevalent subtype of amblyopia was anisometropic amblyopia (57.1\%, [95\% CI, 43.24-70.96]).

Conclusions: Considering the prevalence of amblyopia among schoolchildren aged 7-9 years old (1.7\%), timely detection of amblyopia through preschool screening programs is essential for early treatment or prevention of further visual impairment during childhood.
\end{abstract}

\section{KEY WORDS}

amblyopia, prevalence, elementary school, preschool children, Iran, Mashhad, diagnostic screening program

\section{INTRODUCTION}

Amblyopia is defined as a non-organic loss of bilateral or unilateral best-corrected visual acuity (BCVA). It is reversible if is diagnosed timeously and managed properly [1]. A recently published meta-analysis reported that the worldwide prevalence of amblyopia in children is $4.3 \%$. In a subgroup analysis, the prevalence rate was estimated to be highest in the USA and Europe ( $5.57 \%$ and $4.57 \%$, respectively) and lowest in Asia and Africa ( $3.80 \%$ and $0.71 \%$, respectively) [2]. BCVA equal to or worse than $20 / 40$ (Snellen equivalent $6 / 12$; logarithm of the minimal angle of resolution [logMAR] score 0.3$)$ in one or both eyes has been suggested as a clinical cut-off level for the diagnosis of amblyopia in some studies [3, 4], while others have used a clinical cut-off level of 20/30

Correspondence: Saeed Shahpary, Department of Optometry, School of Rehabilitation Sciences, Shahid Beheshti University of Medical Sciences, Tehran, Iran. E-mail: sa.shahpari@gmail.com. ORCID iD: https://orcid.org/0000-0003-1842-2773

How to cite this article: Shahpary S, Ramin S, Azimi A, Heyrani M. The prevalence of amblyopia in 7-9-year-old schoolchildren in Mashhad. Med Hypothesis Discov Innov Optom.2021 Spring; 2(1): 18-23. DOI: https://doi.org/10.51329/mehdioptometry121

Received: 21 December 2020 Accepted: 12 February 2021

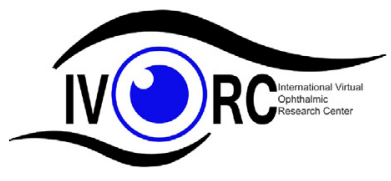

Copyright (C) Author(s). This is an open-access article distributed under the terms of the Creative Commons Attribution-NonCommercial 4.0 International License (http://creativecommons.org/licenses/by-nc/4.0/) which permits copy and redistribute the material just in noncommercial usages, provided the original work is properly cited. (c) (i) (\$) 
(Snellen equivalent 6/9; logMAR score 0.17 ) or worse [5-7]. An additional criterion is the interocular difference in visual acuity of two or more lines, without any pathological cause $[8,9]$.

Unfortunately, late diagnosis and inappropriate management of amblyopia at preschool ages can lead to difficulties in learning and educational ability in schoolchildren, and may lead to permanent social problems [1012]. Considering this issue, one of the most important objectives of the World Health Organization is to raise population awareness concerning visual disorders, such as amblyopia and refractive error during childhood [13]. Preschool screening plays an important role in the early diagnosis and appropriate management of amblyopia, to prevent permanent visual disorders [14], as treatment at an older age may affect the outcome $[15,16]$. To formulate an appropriate strategy for the early diagnosis of amblyopia [17], it is essential to specify the prevalence of this disorder in children.

The aim of current study was thus to determine the prevalence rate of amblyopia in 7-9-years-old children in Mashhad, Iran.

\section{METHODS}

This was a cross-sectional, community-based study, performed in a single school calendar year (2015-2016), on 7-9-year-old schoolchildren, from seven educational districts of Mashhad city, Iran. The study was approved by the Ethics Committee of Shahid Beheshti University of Medical Sciences, and all procedures adhered to the principles of the Declaration of Helsinki. Written informed consent was obtained from the parents or legal guardians of all the patients, prior to conducting any examinations.

Amblyopia was diagnosed based on the following criteria: BCVA in one or both eyes equal or worse than 20/40 (Snellen equivalent 6/12; logMAR score 0.3 ) or an interocular difference of more than two lines in bestcorrected visual acuity without any significant organic pathology (designated as the conventional criterion) [18].

The students in the first, second, and third grades of elementary school, in a single school calendar year (2015-2016), were selected using cluster random sampling. We aimed to select schools such that students of all socio-economic status levels and cultural diversity could uniformly participate. Using cluster sampling, we randomly selected 20 of 189 elementary schools (three schools per district, 10 male-segregated, and 10 female-segregated schools) from a proportional combination of public schools throughout Mashhad. To ensure balance between the all-boy and all-girl schools, we randomly chose two schools in district 3 . The exclusion criteria were parental unwillingness to participate in the study and intolerably poor cooperation of the child during examination. One subject was excluded due to parents' unwillingness. To minimize the probability of ethnic diversity we excluded immigrant students. Additionally, mentally challenged students were excluded from the study.

Initially, basic vision examinations including measurement of uncorrected and corrected visual acuity with a tumbling E-chart at a distance of $6 \mathrm{~m}$, cover testing with an appropriate near $(40 \mathrm{~cm})$ and distance $(6 \mathrm{~m})$ accommodative target, and fundus examination by means of direct ophthalmoscopy (Keeler Practitioner, Windsor, UK). Students who had a BCVA equal to or worse than 20/30 (Snellen equivalent 6/9; LogMAR score 0.17 ) in each eye, or an interocular VA difference of more than two lines, who were not suffering from any pathology of the ocular media and retina, were suspected of having amblyopia and underwent further supplementary visual tests.

Supplementary visual tests, including objective cycloplegic refraction using a Heine $\beta$-200 retinoscope (HEINE Optotechnik, Herrsching, Germany) and MSD trial lenses (MSD Meniscus Trial Lenses, Busto Arsizio, Italy), which were refined by subjective cycloplegic refraction, and a more precise measurement of BCVA following optimal optical correction, was conducted for all children suspected of having amblyopia. To achieve cycloplegia, one drop of 1\% cyclopentolate eye drops (Cyclogyl; Alcon Laboratories, Fort Worth, TX, USA) was instilled three times in each eye, at an interval of $10 \mathrm{~min}$.

Data were analyzed using IBM SPSS Statistics software (version 20.0; IBM Corp., Armonk, NY, USA). We utilized descriptive data analyses, and the prevalence rates of the study were estimated in percentages and $95 \%$ confidence intervals (CIs). The design effect of a cluster random sampling approach was considered and adjusted for in the calculation of standard errors.

\section{RESULTS}

Between November 2015 and February 2016, 2831 children aged 7-9 years attending elementary schools in seven education districts of Mashhad were examined. The 2831 students were almost equally distributed across three grades: 971 (34.3\%) were from grade 1, 925 (32.7\%) from grade 2, and 935 (33\%) from grade 3 . Of the participants, 1670 (59\%) and 1161 (41\%) were boys and girls, respectively. 
Table 1. Prevalence of amblyopia among 2831 screened 7-9-year-old schoolchildren in Mashhad, Iran

\begin{tabular}{|l|l|}
\hline Variable & Value \\
\hline Non-amblyopic, $\mathbf{n}(\%),(95 \% \mathbf{C I})$ & $2782(98.3),(97.82-98.78)$ \\
\hline Amblyopia, n (\%), (95\% CI) & $49(1.7),(1.22-2.18)$ \\
\hline Right eye with amblyopia n (\%) & $20(40.8)$ \\
\hline Left eye with amblyopia, n (\%) & $9(18.4)$ \\
\hline Both eyes with amblyopia, $\mathbf{n}(\%)$ & $20(40.8)$ \\
\hline Grade $\mathbf{1}$ Elementary School, n (\%) & $24(49.0)$ \\
\hline Grade 2 Elementary School, n (\%) & $15(30.6)$ \\
\hline Grade 3 Elementary School, n(\%) & $10(20.4)$ \\
\hline
\end{tabular}

Abbreviations: BCVA, best corrected visual acuity; n, number; CI, confidence interval. Note: diagnostic criteria of study for amblyopia was $B C V A<20 / 40$ or interocular difference of $\mathrm{BCVA}>2$ lines.

Table 2. Frequency of the causes of amblyopia and type of refractive error in 49 students with amblyopia among 2831 7-9-year-old schoolchildren in Mashhad, Iran

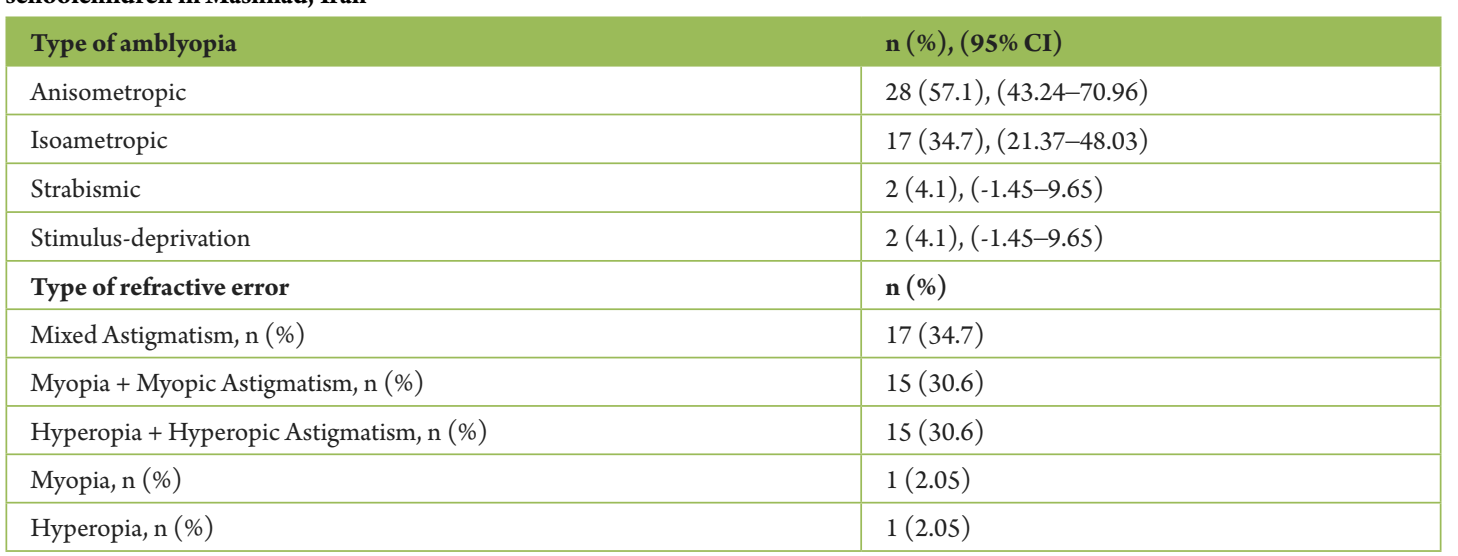

Abbreviations: n, number; \%, percentage; CI, confidence interval. Note: the diagnostic criterion for amblyopia used in this study was Best corrected visual acuity $($ BCVA $)<20 / 40$ or interocular difference of $B C V A>2$ lines.

All students were examined comprehensively by an experienced optometrist. Using the diagnostic criteria of this study, amblyopia was detected in $49 / 2831$ students, indicating a prevalence of $1.7 \%$ ( $95 \%$ confidence interval [CI]: 1.22-2.18). Table 1 shows the prevalence of amblyopia in 7-9-year-old schoolchildren in Mashhad based on the diagnostic criteria of BCVA $<20 / 40$ or interocular difference of BCVA $>2$ lines. Most participants with amblyopia were from grade 1 (49\%), and in more than $80 \%$ of students with amblyopia, either the right eye or both eyes were affected.

Table 2 shows the prevalence of the four subtypes of amblyopia and the frequency of refractive errors among students with amblyopia. Essentially, we found no cases of mixed (strabismic/anisometropic) amblyopia. Among the 49 amblyopic students, the most prevalent subtype of amblyopia was anisometropic amblyopia. The prevalence of the four subtypes of amblyopia in order of frequency was $1 \%, 0.6 \%, 0.07 \%$, and $0.07 \%$ for anisometropic amblyopia, isoametropic amblyopia, strabismic amblyopia, and deprivation amblyopia, respectively. Among the 49 amblyopic students, the most prevalent subtype of refractive error was mixed astigmatism.

\section{DISCUSSION}

BCVA less than 20/40 or an interocular difference of BCVA of more than two lines was considered as the clinical cut-off level for the diagnosis of amblyopia in this study. The results revealed that the prevalence of amblyopia in the first three grades of elementary school was $1.7 \%$ (95\% CI, 1.22-2.18).

Besides the criteria applied and the study population, the method of screening differs greatly between countries [19-23]. Some countries utilize only visual acuity tests for screening amblyopia, whereas others only consider amblyopia risk factors, such as anisometropia, as a screening tool [21,24-26]. Most countries use customary visual acuity charts, which lack precise internal and external reproducibility [22, 27, 28]. These issues cause inaccurate estimates of the prevalence of amblyopia [28]. Table 3 summarizes the information regarding previous studies conducted on the prevalence of amblyopia in several cities in Iran. The reported prevalence rates may differ because of the abovementioned factors [3, 5-7, 29-34]. 
Table 3. Community-based studies on the prevalence of amblyopia in Iran

\begin{tabular}{|l|l|l|l|}
\hline Author (Year of Publication) & Place of study & Sample Size (n) & Prevalence of Amblyopia (\%) \\
\hline Fotouhi et al. (2004) [29] & Tehran & 4565 & 2.7 \\
\hline Shahrirari et al. (2007) [30] & Zahedan & 5446 & 2.2 \\
\hline Jamali et al. (2009) [3] & Shahroud & 815 & 1.7 \\
\hline Yekta et al. (2010) [6] & Shiraz & 2638 & 2.29 \\
\hline Faghihi et al. (2011) [5] & Mashhad & 2510 & 1.9 \\
\hline Hashemi et al. (2014) [7] & Seven cities & 3675 & 1.88 \\
\hline Moradabadi et al. (2014) [31] & Bandar Abbas & 16599 & 1.01 \\
\hline Rajavi et al. (2015) [32] & Tehran & 2410 & 2.3 \\
\hline Yekta et al. (2016) [33] & Mashhad & 3701 & 0.41 \\
\hline Yekta et al. (2017) [34] & Dezful & 1375 & 2.7 \\
\hline Current study & Mashhad & $\mathbf{2 8 3 1}$ & $\mathbf{1 . 7}$ \\
\hline
\end{tabular}

Abbreviations: n, number; \%, percentage.

The findings of the present study are strongly in agreement with the findings of a study conducted by Jamali et al. [3] in Shahroud, which could be attributed to the fact that both studies used the same diagnostic criteria for amblyopia (BCVA less than 20/40 and interocular difference of more than two lines).

Our results revealed a higher rate of amblyopia in the right eye $(40.8 \%)$ than in the left eye (18.4\%) in children with unilateral amblyopia. This result was in contrast with some reports that found that the left eye is more affected in unilateral amblyopia $[3,35,36]$.

In a population-based study in Mashhad, Faghihi et al. found that the causes of amblyopia, in decreasing order, were anisometropic amblyopia, isometropic, mixed (strabismic/anisometropic), and strabismic amblyopia [37]. Likewise, we found anisometropic and isoametropic amblyopia as the first two common causes, while the strabismic type was the least common. However, there were no cases of strabismic/anisometropic amblyopia, and two students with deprivation amblyopia accounted for $4.1 \%$ of amblyopic patients [37]. In contrast, the total prevalence of amblyopia was $1.7 \%$ in our study, whereas a previous study reported a $4.6 \%$ prevalence rate. This difference could arise from a wider age range (3-90 years of age) in Faghihi et al. 's study [37], in contrast to the narrow age range (7-9 years of age) in this study.

A limitation of the current study was the selection of participants only from the first three grades of elementary school. Other limitations were its cross-sectional design and lack of follow-up for the treatment and management of patients with amblyopia. Therefore, our findings should be cautiously generalized to society. Future longitudinal studies with a wider range of participants, including students from all grades, and pre-school children could provide more reliable findings for health policymakers to manage this reversible cause of blindness.

\section{CONCLUSIONS}

Considering the prevalence of amblyopia in our study participants (1.7\%), the importance of timely detection of amblyopia for early treatment or prevention of further visual impairment during childhood, by implementing preschool screening programs, is essential.

\section{ETHICAL DECLARATIONS}

Ethical approval: The study was approved by the Ethics Committee of Shahid Beheshti University of Medical Sciences, and all procedures adhered to the principles of the Declaration of Helsinki. Written informed consent was obtained from the parents or legal guardians of all patients prior to the examination.

\section{Conflict of interests: None.}

\section{FUNDING}

\section{None.}




\section{ACIKNOWLEGMENTS}

We thank all the students who participated in this study and the specific assistance of their parents or legal guardians. Furthermore, we would like to thank school officials for providing a suitable environment for conducting this study.

\section{REFERENCES}

1. Brown SA, Weih LM, Fu CL, Dimitrov P, Taylor HR, McCarty CA. Prevalence of amblyopia and associated refractive errors in an adult population in Victoria, Australia. Ophthalmic Epidemiology. 2000;7(4):249-58. doi: 10.1076/0928-6586(200012)741-yft249 pmid: 11262672

2. Mostafaie A, Ghojazadeh M, Hosseinifard H, Manaflouyan H, Farhadi F, Taheri N, et al. A systematic review of Amblyopia prevalence among the children of the world. Rom J Ophthalmol. 2020;64(4):342-55. doi: 10.22336/rjo.2020.56 pmid: 33367172

3. Jamali P, Fotouhi A, Hashemi H, Younesian M, Jafari A. Refractive errors and amblyopia in children entering school: Shahrood, Iran. Optom Vis Sci. 2009;86(4):364-9. doi: 10.1097/OPX.0b013e3181993f42 pmid: 19289975

4. Xiao O, Morgan IG, Ellwein LB, He M, Refractive Error Study in Children Study G. Prevalence of Amblyopia in School-Aged Children and Variations by Age, Gender, and Ethnicity in a Multi-Country Refractive Error Study. Ophthalmology. 2015;122(9):1924-31. doi: 10.1016/j.ophtha.2015.05.034 pmid: 26278861

5. Faghihi M, Ostadimoghaddam H, Yekta AA. Amblyopia and strabismus in Iranian schoolchildren, Mashhad. Strabismus. 2011;19(4):147-52. doi: 10.3109/09273972.2011.622341 pmid: 22107119

6. Yekta A, Fotouhi A, Hashemi H, Dehghani C, Ostadimoghaddam H, Heravian J, et al. The prevalence of anisometropia, amblyopia and strabismus in schoolchildren of Shiraz, Iran. Strabismus. 2010;18(3):104-10. doi: 10.3109/09273972.2010.502957 pmid: 20843187

7. Hashemi H, Yekta A, Jafarzadehpur E, Nirouzad F, Ostadimoghaddam H, Eshrati B, et al. The prevalence of amblyopia in 7-year-old schoolchildren in Iran. Strabismus. 2014;22(4):152-7. doi: 10.3109/09273972.2014.971824 pmid: 25335186

8. Barrett BT, Bradley A, Candy TR. The relationship between anisometropia and amblyopia. Prog Retin Eye Res. 2013;36:120-58. doi: 10.1016/j.preteyeres.2013.05.001 pmid: 23773832

9. Lim HT, Yu YS, Park SH, Ahn H, Kim S, Lee M, et al. The Seoul Metropolitan Preschool Vision Screening Programme: results from South Korea. Br J Ophthalmol. 2004;88(7):929-33. doi: 10.1136/bjo.2003.029066 pmid: 15205240

10. Carlton J, Karnon J, Czoski-Murray C, Smith KJ, Marr J. The clinical effectiveness and cost-effectiveness of screening programmes for amblyopia and strabismus in children up to the age of 4-5 years: a systematic review and economic evaluation. Health Technol Assess. 2008;12(25):iii, xi-194. doi: 10.3310/hta12250 pmid: 18513466

11. Benetti Zagui RM (2019). 'Amblyopia: Types, Diagnosis, Treatment, and New Perspectives'. American Academy of Ophthalmology, ONE Network. Available at: https://www.aao.org/disease-review/amblyopia-types-diagnosis-treatment-new-perspectiv. (Accessed: June 07, 2021)

12. Newman DK, East MM. Prevalence of amblyopia among defaulters of preschool vision screening. Ophthalmic Epidemiol. 2000;7(1):67-71. pmid: 10652173

13. Dandona R, Dandona L. Refractive error blindness. Bull World Health Organ. 2001;79(3):237-43. Epub 2003 Jul 7. pmid: 11285669

14. Ravindran M, Pawar N, Renagappa R, Ravilla T, Khadse R. Identifying barriers to referrals in preschool-age ocular screening in Southern India. Indian J Ophthalmol. 2020;68(10):2179-84. doi: 10.4103/ijo.IJO_1603_19 pmid: 32971635

15. Holmes JM, Levi DM. Treatment of amblyopia as a function of age. Vis Neurosci. 2018;35:E015. doi: 10.1017/S0952523817000220 pmid: 29905125

16. Webber AL, Wood J. Amblyopia: prevalence, natural history, functional effects and treatment. Clin Exp Optom. 2005;88(6):365-75. doi: 10.1111/j.1444-0938.2005.tb05102.x pmid: 16329744

17. Committee on P, Ambulatory Medicine Section on O, American Association of Certified O, American Association for Pediatric O, Strabismus, American Academy of O. Eye examination in infants, children, and young adults by pediatricians: organizational principles to guide and define the child health care system and/or improve the health of all children. Ophthalmology. 2003;110(4):860-5. doi: 10.1016/S0161-6420(03)00414-7 pmid: 12689914

18. Ohlsson J. Defining amblyopia: the need for a joint classification. Strabismus. 2005;13(1):15-20. doi: 10.1080/09273970590890949 pmid: 15824012

19. Ohlsson J, Villarreal G, Sjostrom A, Abrahamsson M, Sjostrand J. Screening for amblyopia and strabismus with the Lang II stereo card. Acta Ophthalmol Scand. 2002;80(2):163-6. doi: 10.1034/j.1600-0420.2002.800208.x pmid: 11952482

20. Tan JH, Thompson JR, Gottlob I. Differences in the management of amblyopia between European countries. Br J Ophthalmol. 2003;87(3):291-6. doi: 10.1136/bjo.87.3.291 pmid: 12598440

21. Matta NS, Singman EL, Silbert DI. Performance of the plusoptiX S04 photoscreener for the detection of amblyopia risk factors in children aged 3 to 5. J AAPOS. 2010;14(2):147-9. doi: 10.1016/j.jaapos.2010.01.006 pmid: 20451857

22. Powell C, Hatt SR, Powell C. Vision screening for amblyopia in childhood. The Cochrane Library. 2009 Jul 8; (3):CD005020. doi: 10.1002/14651858.CD005020.pub3 pmid: 19588363

23. Logan NS, Gilmartin B. School vision screening, ages 5-16 years: the evidence-base for content, provision and efficacy. Ophthalmic Physiol Opt. 2004;24(6):481-92. doi: 10.1111/j.1475-1313.2004.00247.x pmid: 15491475

24. Konig HH, Barry JC. Economic evaluation of different methods of screening for amblyopia in kindergarten. Pediatrics. 2002;109(4):e59. doi: 10.1542/peds.109.4.e59 pmid: 11927732

25. Lagreze WA. Vision screening in preschool children: do the data support universal screening? Dtsch Arztebl Int. 2010;107(28-29):4959. doi: 10.3238 /arztebl.2010.0495 pmid: 20703333

26. König H-H, Barry J-C. Cost-Utility Analysis of Orthoptic Screening in Kindergarten: A Markov Model Based on Data From Germany. Pediatrics. 2004 Feb;113(2):e95-108. doi: 10.1542/peds.113.2.e95 pmid: 14754978

27. Groenewoud JH, Tjiam AM, Lantau VK, Hoogeveen WC, de Faber JT, Juttmann RE, et al. Rotterdam AMblyopia screening effectiveness study: detection and causes of amblyopia in a large birth cohort. Invest Ophthalmol Vis Sci. 2010;51(7):3476-84. doi: 10.1167/ iovs.08-3352 pmid: 20089868

28. Ohlsson J, Sjöstrand J. Preschool vision screening: is it worthwhile? Pediatric Ophthalmology, Neuro-Ophthalmology. Genetics: Springer. 2006:19-36. doi: 10.1007/3-540-31220-x_2

29. Fotouhi A, Hashemi H, Mohammad K, Jalali KH, Tehran Eye S. The prevalence and causes of visual impairment in Tehran: the Tehran Eye Study. Br J Ophthalmol. 2004;88(6):740-5. doi: 10.1136/bjo.2003.031153 pmid: 15148203 
30. Shahriari HA, Izadi S, Rouhani MR, Ghasemzadeh F, Maleki AR. Prevalence and causes of visual impairment and blindness in Sistan-va-Baluchestan Province, Iran: Zahedan Eye Study. Br J Ophthalmol. 2007;91(5):579-84. doi: 10.1136/bjo.2006.105734 pmid: 17124245

31. Moradabadi AS, Ghanbarnejad A, Bani-Hashemi A, Pourshoorijeh LT, Tofighi M, Zamzam T, et al. Amblyopia screening in children in Bandar Abbas (Iran) during 2011-2012. Electron Physician. 2014;6(3):906-11. doi: 10.14661/2014.906-911 pmid: 25763166

32. Rajavi Z, Sabbaghi H, Baghini AS, Yaseri M, Moein H, Akbarian S, et al. Prevalence of Amblyopia and Refractive Errors Among Primary School Children. J Ophthalmic Vis Res. 2015;10(4):408-16. doi: 10.4103/2008-322X.176909 pmid: 27051485

33. Yekta A, Hashemi H, Ostadimoghaddam H, Haghighi B, Shafiee H, Mehravaran S, et al. Strabismus and Near Point of Convergence and Amblyopia in 4-6 Year-Old Children. Strabismus. 2016;24(3):113-9. doi: 10.1080/09273972.2016.1205103 pmid: 27485705

34. Yekta A, Hashemi H, Norouzirad R, Ostadimoghaddam H, Nabovati P, Dadbin N, et al. The Prevalence of Amblyopia, Strabismus, and Ptosis in Schoolchildren of Dezful. Eur J Ophthalmol. 2017;27(1):109-12. doi: 10.5301/ejo.5000795 pmid: 27228971

35. Ikuomenisan SJ, Musa KO, Aribaba OT, Onakoya AO. Prevalence and pattern of amblyopia among primary school pupils in Kosofe town, Lagos state, Nigeria. Niger Postgrad Med J. 2016;23(4):196-201. doi: 10.4103/1117-1936.196261 pmid: 28000640

36. Robaei D, Kifley A, Rose KA, Mitchell P. Impact of amblyopia on vision at age 12 years: findings from a population-based study. Eye (Lond). 2008;22(4):496-502. doi: 10.1038/sj.eye.6702668 pmid: 17384576

37. Faghihi M, Hashemi H, Nabovati P, Saatchi M, Yekta A, Rafati S, et al. The Prevalence of Amblyopia and Its Determinants in a Population-based Study. Strabismus. 2017;25(4):176-83. doi: 10.1080/09273972.2017.1391849 pmid: 29144181 